\title{
Effects of Antisense to the $\alpha 2 A$-Adrenoceptors Administered into the Region of the Locus Ceruleus on Behaviors in Plus-Maze and Sexual Behavior Tests in Sham-Operated and Castrated Male Rats
}

\author{
Galina T. Shishkina, Tatjana S. Kalinina, Natalja Yu. Sournina, and Nikolai N. Dygalo \\ Institute of Cytology and Genetics, Russian Academy of Sciences, Novosibirsk 630090, Russia
}

Clinical and experimental findings have implicated brain $\alpha 2-$ adrenoceptors in the regulation of many physiological functions, including sexual activity and stress-related behavior. However, which subtypes of the three $\alpha 2$-adrenoceptors that have now been cloned $(\alpha 2 \mathrm{~A}, \alpha 2 \mathrm{~B}$, and $\alpha 2 \mathrm{C})$ are involved in these controls have yet to be established. Here, we investigated the contribution of $\alpha 2 \mathrm{~A}$-adrenoceptors of the locus ceruleus, the principal source of brain noradrenaline, to exploratory and sexual behaviors. Using administration of antisense oligodeoxynucleotide to inhibit the receptor expression, we found that reductions in brainstem $\alpha 2 \mathrm{~A}$-adrenoceptor mRNA levels and $\alpha 2$-adrenoceptor densities induced by antisense treatment were not accompanied by any changes in the major characteristics of male sexual activity, such as mount latencies and numbers of mounts. However, in sexual behavior tests, antisensetreated male rats had decreased numbers of rearings and thus have higher percentages of behaviors positively correlated with sexual activity. Besides, antisense-treated animals had decreased anxiety in plus-maze tests. The data demonstrate that inhibition of $\alpha 2 \mathrm{~A}$-adrenoceptor expression in the region of the locus ceruleus has an anxiolytic-like effect and facilitates male's attention to female in sexual behavior test.

Key words: $\alpha 2 A$-adrenoceptors; locus ceruleus; anxiety; male sexual behavior; antisense oligodeoxynucleotide; $m R N A$
Pharmacological studies have implicated brain $\alpha 2$-adrenoceptors in the regulation of male sexual behavior (for review, see Bancroft, 1995; Rampin, 1999). Administration of the receptor agonists have been shown to inhibit copulatory activity in male rats (Clark et al., 1985a; Clark, 1991; Benelli et al., 1993), whereas the receptor antagonists enhance their sexual motivation (Clark and Smith, 1984; Clark et al., 1985a,b; Smith et al., 1987; Peters et al., 1988; Sala et al., 1990; Koskinen et al., 1991; Benelli et al., 1993; Tallentire et al., 1996; Spedding et al., 1998). $\alpha 2$-Adrenoceptors have been subdivided into three distinct subtypes: $\alpha 2 \mathrm{~A}, \alpha 2 \mathrm{~B}$, and $\alpha 2 \mathrm{C}$ (Bylund et al., 1994). However, which subtypes of the receptors are involved in the control of male sexual behavior have yet to be established.

It has been reported that systemic administration of $\alpha 2$ adrenoceptor antagonists that facilitate sexual behavior are accompanied by an increased noradrenergic transmission in brain regions that receive noradrenergic innervation (Dennis et al., 1987; Szemeredi et al., 1991; Gobert et al., 1997). A majority of noradrenergic neurons are located in the locus ceruleus that project to the cortex and to most subcortical areas. Autoreceptor control of noradrenaline release in the locus ceruleus is mediated by $\alpha 2 \mathrm{~A}$-adrenoceptors (Callado and Stamford, 1999). In the present study, the involvement of the $\alpha 2 \mathrm{~A}$-adrenoceptors of the locus ceruleus in the regulation of male sexual behavior was explored. For this, we examined possible alterations in sexual behavior in sham-operated and castrated male rats after injections of an antisense oligodeoxynucleotide complementary to the $\alpha 2 \mathrm{~A}$-adrenoceptor mRNA into the region of the locus ceruleus.

\footnotetext{
Received July 28, 2000; revised Oct. 31, 2000; accepted Nov. 1, 2000.

This work was supported by Russian Fund for Basic Research Grants N 98-0449651 and N 99-04-50022.

Correspondence should be addressed to N. N. Dygalo, Institute of Cytology and Genetics, Novosibirsk 630090, Russia. E-mail: dygalo@bionet.nsc.ru.

Copyright (C) 2001 Society for Neuroscience $0270-6474 / 01 / 210726-06 \$ 15.00 / 0$
}

In addition to sexual behavior, anxiety of the animals in the elevated plus-maze test was evaluated after administration of this antisense because the changes in locus ceruleus noradrenergic function appear to influence anxious behavior (Bremner et al., 1996a,b). We also measured the levels of $\alpha 2 \mathrm{~A}$-adrenoceptor mRNA, binding of $\alpha 2$ - and $\beta$-adrenoceptors, and concentrations of noradrenaline and dopamine in the brain to estimate the specificity of antisense effect on the expression of $\alpha 2 \mathrm{~A}$-adrenoceptors.

\section{MATERIALS AND METHODS}

Animals and experimental procedures. Adult male Wistar rats (225-240 $\mathrm{gm})$ were housed under conditions of natural illumination with food and water available ad libitum. All animal use procedures conformed to international European ethical standards (86/609-EEC) and the Russian national instructions for the care and use of laboratory animals. Animals were either bilaterally castrated or underwent a sham operation under ether anesthesia.

Twenty-four days after the surgery, a steel cannula was implanted in the vicinity of the locus ceruleus $(9.5 \mathrm{~mm}$ caudal to bregma and $5.9 \mathrm{~mm}$ below the skull) under Nembutal anesthesia $(40 \mathrm{mg} / \mathrm{kg}$, i.p.). Both sham-operated and castrated groups were then subdivided into three subgroups (each subgroup consisted of six animals). Four days after insertion of the cannula, rats of the first subgroups were injected three times continuously for $3 \mathrm{~d}$ with $1 \mathrm{nmol}$ with $5 \mu \mathrm{l}$ per day antisense phosphorotioate oligodeoxynucleotide to $\alpha 2 \mathrm{~A}$-adrenoceptor mRNA. The antisense was targeted to the area that bridges the initiation codon (from -11 to $+7,5^{\prime}$-agcccatgggcgcaaagc- $3^{\prime}$ ). Animals of the two control subgroups received infusions of a phosphorotioate-modified oligodeoxynucleotide containing the same nucleotides as antisense, but in random sequence $\left(5^{\prime}\right.$-gacgaccagtgagcacg- $\left.3^{\prime}\right)$, or saline. The sequences of antisense and random have relatively low homology with any of the other known mammalian sequences found in the GenBank database.

Behavioral tests were conducted on days 2 and 3 of the infusion. All animals were decapitated $24 \mathrm{hr}$ after the last injection. Frontal cortex, hippocampus, and brainstem were rapidly dissected out on a cooled plate and frozen in liquid nitrogen. Frontal cortex sample included tissue sections of 1.5-mm-thick cut from the upper surface of the frontal half of the hemispheres. Brainstem sample included pons and medulla oblongata. The levels of $\alpha 2 \mathrm{~A}$-adrenoceptor mRNA (reverse transcription- 
A

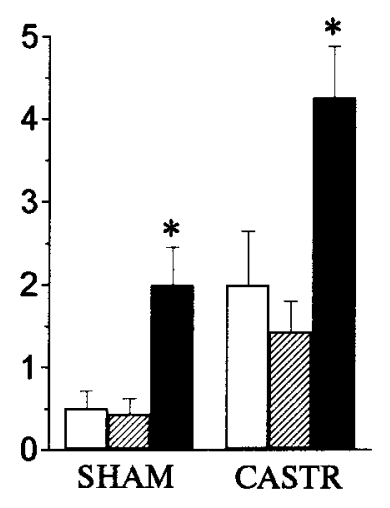

SALINE
RANDOM
B

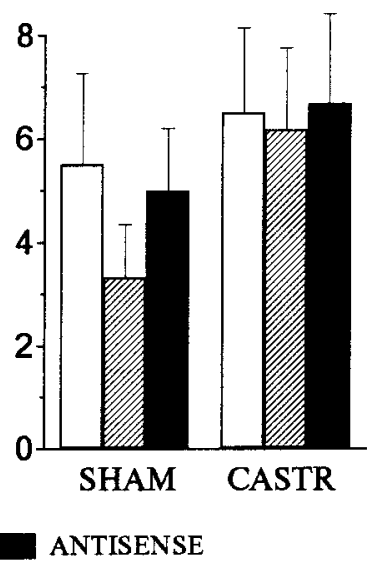

ANTISENSE
$\mathrm{C}$

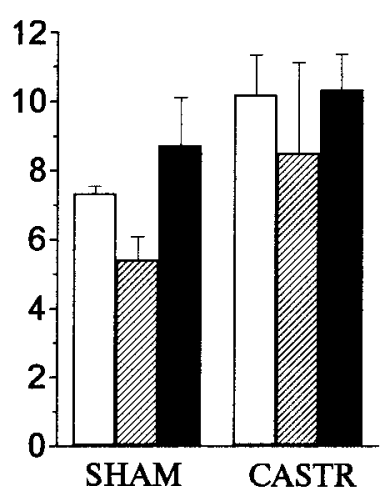

Figure 1. Numbers of entries in the open arms of the plus maze $(A)$, total arm entries $(B)$, and rearings $(C)$ made by shamoperated $(S H A M)$ and castrated $(C A S T R)$ males after injections of antisense oligodeoxynucleotide to the $\alpha 2 \mathrm{~A}$-adrenoceptors, oligodeoxynucleotide of a random sequence, or saline into the region of the locus ceruleus. ${ }^{*} p<0.05$ versus saline and random.
PCR), numbers of $\alpha 2$ - and $\beta$-adrenoceptors (radioligand binding of ${ }^{3} \mathrm{H}$-clonidine and ${ }^{3} \mathrm{H}$-dihydroalprenolol), and contents of noradrenaline and dopamine were determined in these regions.

Elevated plus-maze tests. Animals were tested on the elevated plusmaze tests $6 \mathrm{hr}$ after the second injections of drugs between 3:00 P.M. and 4:00 P.M. At the start of the test, rats were placed individually on the center square facing an open arm. During the 5 min test period, the number of entries into both open and closed arms separately and number of rearings were recorded.

Male sexual behavior tests. Sexual behavior tests were conducted $2 \mathrm{hr}$ after the onset of darkness on day 3 of the injections. A receptive female was presented to the male for $20 \mathrm{~min}$. The following measurements were taken: (1) mount latency; (2) number of mounts; (3) number of rearings; (4) number of genital sniffings; (5) number of groomings; and (6) percent of behaviors positively correlated with sexual activity, which was calculated by expressing such behaviors (i.e., number of mounts plus number of groomings) as a percent of the total of scored behaviors (number of mounts plus number of groomings plus number of rearings plus number of genital sniffings).

Analysis of $\alpha 2 A$-adrenoceptor $m R N A$. Total cellular mRNA $(2 \mu \mathrm{m})$ from the brainstem was isolated by a single step acid guanidiniumphenol-chloroform extraction method (Chomczynski and Sacchi, 1987). Two micrograms of total mRNA were used as template for the firststrand cDNA synthesis in $20 \mu \mathrm{l}$ reaction volume containing $67 \mathrm{~mm}$ Tris-HCl, $\mathrm{pH} 8.8,17 \mathrm{~mm} \mathrm{KCl}, 1 \mathrm{~mm} \mathrm{MnCl}$, and $1 \mathrm{~mm}$ each of dNTP, 100 ng of oligo-dT primer, $2.5 \%$ glycerol, and 5 U of TET-z DNA polymerase, which has reverse transcriptase activity in abundance of $\mathrm{Mn}^{2+}$. Reaction temperatures were $25^{\circ} \mathrm{C}$ for $10 \mathrm{~min}$ for annealing of primer, and $42^{\circ} \mathrm{C}$ for $1 \mathrm{hr}$ for extension of primers. After that, $5 \mu \mathrm{l}$ of reaction mixture was increased to $50 \mu \mathrm{l}$ with $45 \mu \mathrm{l}$ of PCR mix (67 mM Tris- $\mathrm{HCl}, \mathrm{pH} 8.0$, $2.5 \mathrm{mM} \mathrm{MnCl}_{2}, 0.01 \mathrm{~m}$ 2-mercaptoethanol, $0.01 \%$ Tween 20, $0.2 \mathrm{~mm}$ of forward and reverse for $\alpha 2 \mathrm{~A}$-adrenoceptor or $\beta$-actin PCR primers, and $2.5 \mathrm{U}$ of Tag polymerase). Oligonucleotide primers were designed from sequences of cytoplasmic $\beta$-actin and $\alpha 2 \mathrm{~A}$-adrenoceptor, which are presented in the GenBank database. Oligonucleotides for $\alpha 2 \mathrm{~A}$-adrenoceptor forward primer sequence were $5^{\prime}$-tgcgagatcaacgaccagaag- $3^{\prime}$ and reverse$5^{\prime}$-cacgaacgtgaagcgcttctc- $3^{\prime}$. The expected size of the amplified fragment was $564 \mathrm{bp}$. For $\beta$-actin, primers were $5^{\prime}$-tccctcatgccatcctgcgt- $3^{\prime}$ and $5^{\prime}$-ggaacctctcattgccgata- $3^{\prime}$ to produce a $255 \mathrm{bp}$ fragment. Amplifications were performed in a programmable thermal cycler with an initial template denaturation at $95^{\circ} \mathrm{C}$ for $3 \mathrm{~min}$, annealing at $52^{\circ} \mathrm{C}$ for $1.5 \mathrm{~min}$, and extension of primers for $2 \mathrm{~min}$ at $70^{\circ} \mathrm{C}$. This first cycle was followed by 40 amplification cycles of denaturation at $95^{\circ} \mathrm{C}$ for $0.8 \mathrm{~min}$, annealing at $52^{\circ} \mathrm{C}$ for $0.8 \mathrm{~min}$, and extension at $70^{\circ} \mathrm{C}$ for $1 \mathrm{~min}$. The final cycle lasted 10 min at $70^{\circ} \mathrm{C}$. In all experiments, the presence of possible contaminants was checked by control reaction in which amplification was performed on samples in which reverse transcriptase was omitted from the reverse transcription reaction mixture. The amplification products were separated on ethidium bromide-stained $1.5 \%$ agarose gel. Gene expression level of $\alpha 2 \mathrm{~A}$-adrenoceptors was quantified relatively to $\beta$-actin by scanning densitometer (Biodoc II video documentation system; Biometra $\mathrm{GmbH}$, Gottingen, Germany).

Analysis of $\alpha 2$ - and $\beta$-adrenoceptor binding sites. Brain tissues were

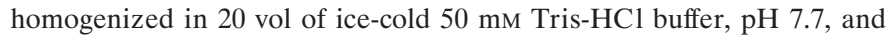
centrifuged at $20,000 \times g$ for $15 \mathrm{~min}$. The pellets were rehomogenized in another portion of the buffer and then centrifuged again. The final pellets were resuspended in $140 \mathrm{vol}$ of the same buffer. ${ }^{3} \mathrm{H}$-Clonidine $(3.2$ $\mathrm{nM} ; 23.2 \mathrm{Ci} / \mathrm{mmol}$ ), imidazoline with $\alpha 2$-adrenoceptor agonist specificity, or $1.6 \mathrm{~nm}{ }^{3} \mathrm{H}$-dihydroalprenolol $\left({ }^{3} \mathrm{H}\right.$-DHA) $(75 \mathrm{Ci} / \mathrm{mmol})$, the $\beta$-adrenoceptor antagonist, were added to $0.8 \mathrm{ml}$ of membrane suspensions, and the samples in final volumes of $1 \mathrm{ml}$ were incubated: for ${ }^{3} \mathrm{H}$-clonidine binding, $30 \mathrm{~min}$ at $25^{\circ} \mathrm{C}$ in the absence (total binding) or presence (nonspecific binding) of $100 \mu \mathrm{M}$ noradrenaline (Koch-Light, Haverhill, UK); for ${ }^{3} \mathrm{H}$-DHA binding, $20 \mathrm{~min}$ at $23^{\circ} \mathrm{C}$ with or without 10 $\mu \mathrm{M}$ propranolol (Sigma, Poole, UK). The reactions were terminated by rapid filtration under a vacuum through glass fiber filters $(\mathrm{GF} / \mathrm{B}$; Whatman, Maidstone, UK). Filters were immediately washed three times with $5 \mathrm{ml}$ of ice-cold buffer, and radioactivity was measured in a Delta-300 liquid scintillation counter. Specific binding was determined by subtracting nonspecific binding from total binding and expressed as femtomoles of radioligand bound per milligram of protein (Shishkina and Naumenko, 1995). Determination of protein was performed by the method of Lowry et al. (1951).

Neurochemical assays. The concentrations of noradrenaline and dopamine were determined fluorimetrically (Jacobowitz and Richardson, 1978).

Statistics. Data were analyzed by using two-way ANOVA for effect of castration and treatment. One-way ANOVA was used for treatment effect within each sham-operated or castrated group. Significant differences were identified by Tukey's post hoc $t$ test.

\section{RESULTS}

\section{Elevated plus maze}

Castration of male rats significantly elevated the numbers of open-arm entries compared with that in sham-operated animals $\left(F_{(1,30)}=18.150 ; p<0.001\right)$ (Fig. 1). Treatment of the rats with antisense to $\alpha 2 \mathrm{~A}$-adrenoceptors increased the numbers of open-arm entries compared with random and saline controls $\left(F_{(2,30)}=12.008\right.$; $p<0.001)$. The effect of treatment was significant for both shamoperated $\left(F_{(2,15)}=8.903 ; p<0.01\right)$ and castrated $\left(F_{(2,15)}=5.572\right.$; $p<0.05)$ rats.

There were no significant differences among groups in total number of arm entries (castration, $F_{(1,30)}=2.148$, NS; treatment, $F_{(2,30)}=0.393$, NS) (Fig. 1).

Numbers of rearings (Fig. 1) were significantly elevated with castration $\left(F_{(1,30)}=4.489 ; p<0.05\right)$. Antisense treatment had no effect on the numbers of rearings in these tests $\left(F_{(2,30)}=1.608\right.$, NS). 
A

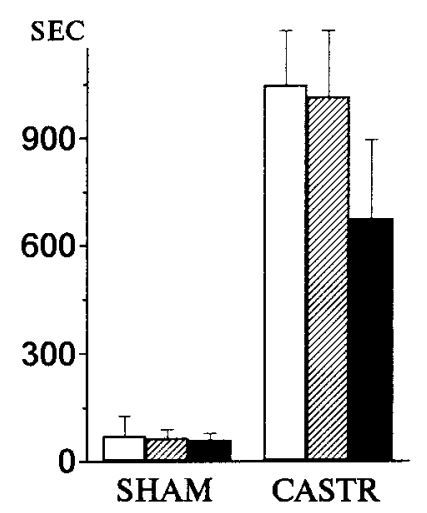

$\mathrm{C}$

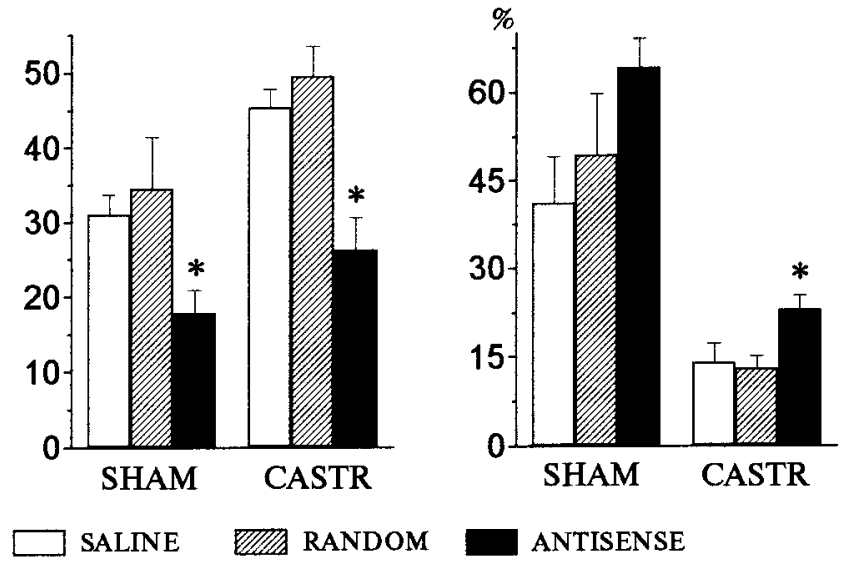

Figure 2. Mount latencies $(A)$, numbers of mounts $(B)$, rearings $(C)$, and percent of behaviors positively correlated with male sexual activity (number of mounts plus number of groomings) $(D)$ shown by shamoperated $(S H A M)$ and castrated $(C A S T R)$ males after injections of antisense oligodeoxynucleotide to the $\alpha 2 \mathrm{~A}$-adrenoceptors, oligodeoxynucleotide of a random sequence, or saline into the region of the locus ceruleus. ${ }^{*} p<0.05$ versus saline and random.

\section{Male sexual behavior tests}

Castration of male rats produced a suppression of copulatory behavior as evidenced by drastic increases in mount latencies $\left(F_{(1,30)}=19.736 ; p<0.001\right)$ and decreases in numbers of mounts $\left(F_{(1,30)}=21.357 ; p<0.001\right)($ Fig. 2). Antisense treatment did not affect the mount latencies $\left(F_{(2,30)}=0.890, \mathrm{NS}\right)$ or numbers of mounts $\left(F_{(2,30)}=0.154\right.$, NS $)$. Although antisense-treated castrated males had shorter mount latencies and greater numbers of mounts than did the control castrated males, none of the differences reached statistical significance.

Castration of animals significantly increase the number of rearings $\left(F_{(1,30)}=10.968 ; p<0.01\right)$ (Fig. 2$)$ and genital sniffings $\left(F_{(1,30)}=\right.$ 7.134; $p<0.001$ ) (data not shown) in sexual behavior tests. Administration of antisense significantly reduced both rearing $\left(F_{(2,30)}=10\right.$. 416; $p<0.001)$ and sniffing $\left(F_{(2,30)}=3.43 ; p<0.05\right)$ numbers. Numbers of groomings that were significantly reduced after castration $\left(F_{(1,30)}=19.833 ; p<0.001\right)$ were not influenced by antisense treatment $\left(F_{(2,30)}=0.062\right.$, NS) (data not shown).

The percent of the behaviors positively correlated with sexual activity (number of mounts plus number of groomings) were
A

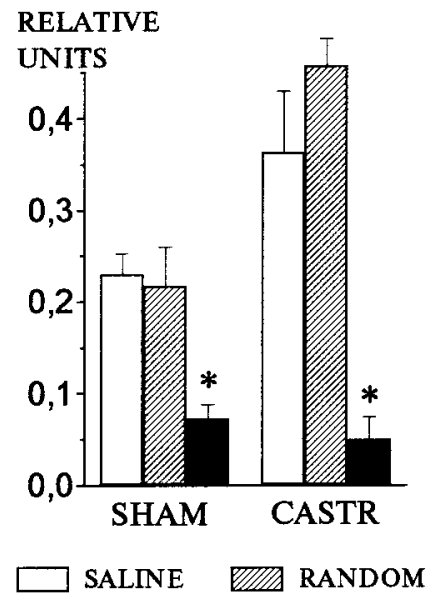

B

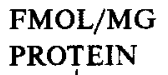

PROTEIN

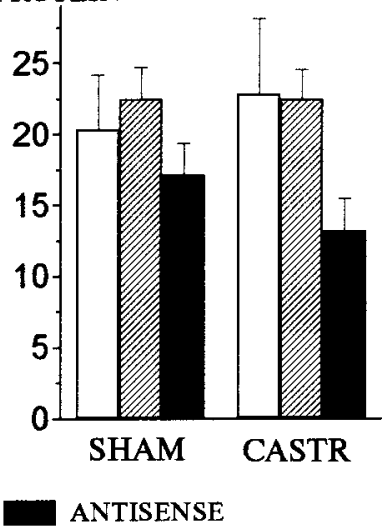

Figure 3. Levels of $\alpha 2 \mathrm{~A}$-adrenoceptor mRNA $(A)$ and ${ }^{3} \mathrm{H}$-clonidine binding $(B)$ in the brainstem of sham-operated (SHAM) and castrated (CASTR) males after injections of antisense oligodeoxynucleotide to the $\alpha 2 \mathrm{~A}$-adrenoceptors, oligodeoxynucleotide of a random sequence, or saline into the region of the locus ceruleus. ${ }^{*} p<0.01$ versus saline and random.

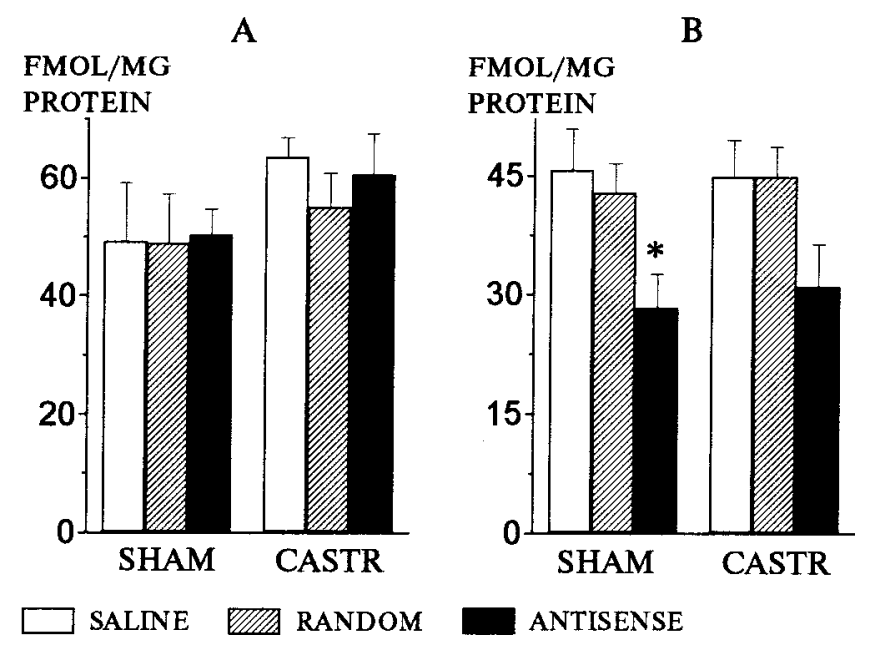

Figure 4. Binding of ${ }^{3} \mathrm{H}$-clonidine in the frontal cortex $(A)$ and hippocampus $(B)$ of sham-operated $(S H A M)$ and castrated $(C A S T R)$ males after injections of antisense oligodeoxynucleotide to the $\alpha 2 \mathrm{~A}$ adrenoceptors, oligodeoxynucleotide of a random sequence, or saline into the region of the locus ceruleus. ${ }^{*} p<0.05$ versus saline and random.

higher in sham-operated animals than in castrated males $\left(F_{(1,30)}\right.$ $=28.100 ; p<0.001$ ) (Fig. 2). There were marginal elevations in the percentages of these behaviors after antisense treatment $\left(F_{(2,30)}=3.208 ; p<0.06\right)$. The elevation reached significance in castrated rats $\left(F_{(2,15)}=3.770 ; p<0.05\right)$.

\section{Expression of $\alpha 2 \mathrm{~A}$-adrenoceptors in the brainstem}

The levels of $\alpha 2 \mathrm{~A}$-adrenoceptor mRNA in the brainstem (Fig. 3) were increased by castration $\left(F_{(1,12)}=8.001 ; p<0.05\right)$ and decreased by administration of antisense into the region of locus ceruleus $\left(F_{(2,12)}=17.301 ; p<0.001\right)$.

The densities of brainstem $\alpha 2$-adrenoceptors (Fig. 3), assessed by ${ }^{3} \mathrm{H}$-clonidine binding, were not changed in castrated males $\left(F_{(1,30)}=\right.$ 0.036 , NS). Marginally significant decreases in ${ }^{3} \mathrm{H}$-clonidine binding were found in this brain region after antisense treatment $\left(F_{(2,30)}=\right.$ 3.075; $p<0.07)$. 
A

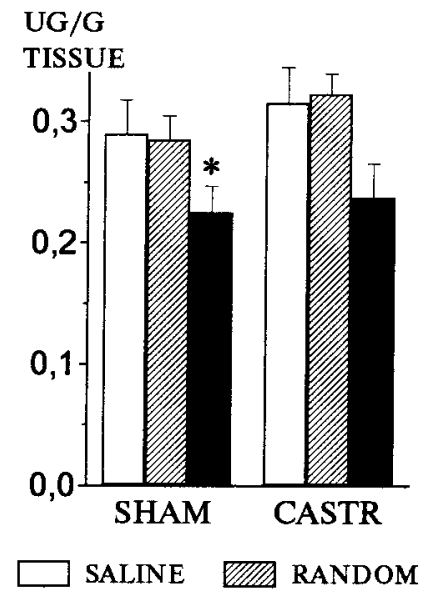

B

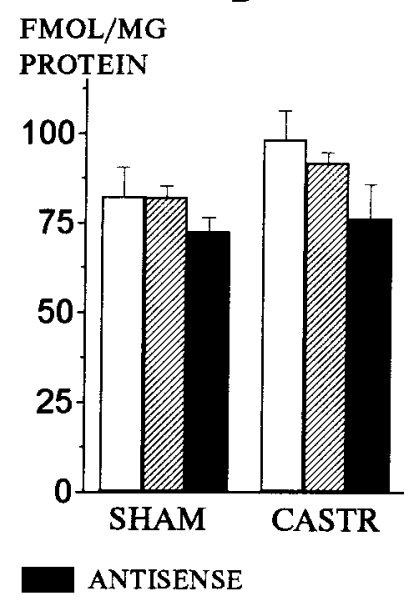

Figure 5. Cortical noradrenaline $(A)$ and ${ }^{3} \mathrm{H}-\mathrm{DHA}$ binding $(B)$ in shamoperated $(S H A M)$ and castrated $(C A S T R)$ males after injections of antisense oligodeoxynucleotide to the $\alpha 2 \mathrm{~A}$-adrenoceptors, oligodeoxynucleotide of a random sequence, or saline into the region of the locus ceruleus. ${ }^{*} p<0.05$ versus random.

\section{${ }^{3} \mathrm{H}$-clonidine binding in the frontal cortex and hippocampus}

The densities of ${ }^{3} \mathrm{H}$-clonidine binding sites in the frontal cortex were significantly increased after castration $\left(F_{(1,30)}=5.471 ; p<\right.$ 0.05 ) (Fig. 4). Administration of antisense into the region of the locus ceruleus did not affect the densities of binding sites in the frontal cortex $\left(F_{(2,30)}=0.760, \mathrm{NS}\right)$.

In the hippocampus (Fig. 4), castration did not modify specific ${ }^{3} \mathrm{H}$-clonidine binding $\left(F_{(1,30)}=0.042\right.$, NS). Treatment with antisense induced a significant reduction in the binding site densities in this brain region $\left(F_{(2,30)}=6.575 ; p<0.01\right)$.

\section{Concentrations of noradrenaline and dopamine, and ${ }^{3} \mathrm{H}$-DHA binding in the frontal cortex}

No significant changes were found in the concentrations of noradrenaline in the frontal cortex of rats after castration $\left(F_{(1,30)}=\right.$ $1.519, \mathrm{NS})$. Antisense treatment caused a significant decrease in cortical noradrenaline concentrations $\left(F_{(2,30)}=5.679 ; p<0.01\right)$ (Fig. 5).

There was no effect of castration $\left(F_{(1,30)}=0.018\right.$, NS) or antisense treatment $\left(F_{(2,30)}=0.028, \mathrm{NS}\right)$ on the concentrations of dopamine in the frontal cortex (data not shown).

A marginally significant elevation in the binding of ${ }^{3} \mathrm{H}-\mathrm{DHA}$ to cortical $\beta$-adrenoceptors (Fig. 5) was seen for the castrated animals $\left(F_{(1,30)}=3.293 ; p<0.08\right)$. Antisense treatment led to a marginally significant reduction in ${ }^{3} \mathrm{H}$-DHA binding in the frontal cortex $\left(F_{(2,30)}=3.225 ; p<0.06\right)$.

\section{DISCUSSION}

The present results showed that administration of antisense to $\alpha 2 \mathrm{~A}$-adrenoceptors into the region of locus ceruleus decreased the level of $\alpha 2 \mathrm{~A}$-adrenoceptor mRNA and the number of $\alpha 2$ adrenoceptors in the brainstem. However, the reduction of the receptor density was only marginal, whereas that of mRNA level was highly significant. One possible reason for this difference is the ability of ${ }^{3} \mathrm{H}$-clonidine to label nonadrenoceptor imidazoline binding sites, in addition to $\alpha 2$-adrenoceptors (Ernsberger et al., 1987). A similar 20-30\% decrement in binding site densities in brain regions close to the side of the intracerebroventricular

infusion of antisense to $\alpha 2 \mathrm{D}$-adrenoceptors has been reported by Robinson et al. (1999) with the other non-subtype selective radioligand ${ }^{3} \mathrm{H}-\mathrm{RX} 821002$.

Treatment with antisense caused reduction in expression of brainstem $\alpha 2$-adrenoceptors in both sham-operated and castrated rats. However, castration itself affected the receptor expression in brain regions. The levels of $\alpha 2$-adrenoceptor mRNA in the brainstem and the densities of $\alpha 2$-adrenoceptors in the frontal cortex were increased in castrated animals 4 weeks after the operation compared with sham-operated males. This is consistent with the previously published report that demonstrated increases in ${ }^{3} \mathrm{H}$ clonidine binding in the cortex 2 and 3 weeks after castration (Shishkina et al., 1997). Although the castrated group started out with a higher level of $\alpha 2 \mathrm{~A}$-adrenoceptor mRNA, antisense treatment lowered it to the same level as the sham-operated antisensetreated animals. Effects of antisense on behavioral assessments in sexual behavioral tests were also more pronounced in castrated rats.

Male sexual behavior depends on testicular hormones (Damassa et al., 1977; Clark et al., 1988; Shishkina et al., 1993). Results from the present and previous studies indicate that $\alpha 2$ adrenoceptors appear to be sensitive to their regulatory influences (Shishkina and Naumenko, 1995; Shishkina et al., 1997). These observations suggest that the stimulatory effects of testosterone on sexual behavior may be attributable to alterations in brain $\alpha 2$-adrenoceptor density. Moreover, ability of the $\alpha 2$ adrenoceptor antagonist yohimbine to facilitate sexual activity in long-term castrated male rats indicate that the $\alpha 2$-adrenergic regulation of sexual behavior is downstream from the effect of testosterone (Clark et al., 1985b).

The locus ceruleus noradrenergic cell group is involved in the formation of the arousal system (Marrocco et al., 1994). However, $\alpha 2 \mathrm{~A}$-adrenoceptors of the locus ceruleus are not important in the control of sexual arousal. Reduction of the $\alpha 2 \mathrm{~A}$-adrenoceptor expression induced by antisense treatment was not accompanied by changes in major characteristics of male sexual activity, such as mount latency and number of mounts. Thus, it seems likely that stimulatory effects of systemic injection of $\alpha 2$-adrenoceptor antagonists on male sexual behavior (Clark et al., 1984, 1985a,b; Smith et al., 1987; Peters et al., 1988; Sala et al., 1990; Koskinen et al., 1991; Benelli et al., 1993; Tallentire et al., 1996; Spedding et al., 1998) occur via other brain regions. For example, Clark (1991) has reported that administration of yohimbine into the medial preoptic area attenuated the inhibitory effect of systemically administered clonidine on sexual activity. At the same time, because in sexual behavior tests genital sniffing in castrated males and rearing in rats of both sham-operated and castrated groups were declined after antisense treatment, percent of behaviors positively correlated with sexual activity (number of mounts plus number of groomings) was increased in these animals. It is important to note that the inhibitory effect of antisense on rearing is specific for the sexual behavior test because, in the other behavioral test, the plus maze, number of rearings did not differ between control and antisense-treated rats. Together, these findings suggest that antisense treatment resulted in a facilitatory effect on male's attention to female but, in general, did not affect copulatory behavior in males.

Antisense administration also modified the function of the noradrenergic system in the target brain regions of the locus ceruleus, such as the frontal cortex and hippocampus. Thus, a significant fall in $\alpha 2$-adrenoceptor densities in the hippocampus was observed after the treatment. This is consistent with the finding that the majority of hippocampal $\alpha 2 \mathrm{~A}$-adrenoceptors ap- 
pear to be associated with fine axons and presynaptically located (Milner et al., 1998). In contrast to the hippocampus, we did not observe any effect of antisense on the $\alpha 2$-adrenoceptor densities in the frontal cortex. The presence of relatively large number of $\alpha 2$-adrenoceptors located postsynaptically and on noncatecholaminergic terminals (Heal et al., 1993; Aoki et al., 1994; Venkatesan et al., 1996) could mask the possible effect of antisense on cortical receptors, which are imported into this region from the brainstem. In the frontal cortex, concentrations of noradrenaline were decreased in antisense-treated animals. This effect can be explained by an enhancement in neuronal firing and release of neurotransmitter. Such a possibility is supported by the finding that infusion of preferential $\alpha 2 \mathrm{~A}$-adrenoceptor antagonist into the locus ceruleus enhanced release of noradrenaline in the cortex (Mateo and Meana, 1999). Because long-term exposure to agonist can change the expression of different adrenoceptors, the tendency for the decrease in cortical $\beta$-adrenoceptor density after antisense treatment may reflect downregulation of this receptor population by continued noradrenaline stimulation (Hosoda et al., 1994, 1995).

Of the brain regions that have been investigated, noradrenergic neurotransmission or $\alpha 2 \mathrm{~A}$-autoreceptors in the frontal cortex may be involved in regulating behaviors in sexual tests by altering the male's reactivity to female stimuli. Thus, adrenergic pathways innervating the cortex play a role in cognito-attentional processes (Marrocco et al., 1994), and it has been shown that male rats with lesions of the cerebral cortex near the midline in the frontal region had very long mount latencies (Agmo and Villalpando, 1995). The involvement of cortical $\alpha 2$-adrenoceptors in sexual behavior is also supported by changes in their expression after castration and copulation (Rago et al., 1992).

The results obtained with the plus maze showed anxiolytic-like effects of long-term castration and antisense administration. Effect of castration may be attributable to the decreased level of testosterone. Thus, it was shown that adult male rats made a lower percentage of entries in the open arms than females. Besides, newborn castration led to an adult male behavioral pattern that resembles that of the female (Lucion et al., 1996). A hypothesis to explain the anxiolytic effect of antisense may be an increase of noradrenergic neurons firing and elevation of synaptic noradrenaline release. This hypothesis is supported by studies showing a decrease in anxiety-related behavior after direct stimulation of the locus ceruleus (Weiss et al., 1994). This is also consistent with the finding that noradrenergic neuronal integrity is required for the anxiolytic-like effects of chronic antidepressant treatment (Fontana et al., 1999). However, we have no comparable data pointing to the $\alpha 2 \mathrm{~A}$-adrenoceptor mechanism whereby novelty leads to anxiety. Pharmacological results reported with $\alpha 2$-adrenoceptor antagonists are quite inconsistent. They span the full range of effects from anxiogenesis (Handley and Mithani, 1984) to anxiolysis (La Marca and Dunn, 1994; Cole et al., 1995). This is discussed in relation to the well known action of the used antagonists on monoaminergic receptors other than $\alpha 2$-adrenoceptors. Nevertheless, our results are consistent with the view that agents with selective antagonism at the $\alpha 2$-adrenoceptor may be anxiolytic, whereas agents with less specificity at this adrenoceptors are not anxiolytic (La Marca and Dunn, 1994; Cole et al., 1995). The divergence in the antagonist effects may be also attributable to the multiplicity of $\alpha 2$ adrenoceptor subtypes and the lack of subtype-specific ligands. The present study provides evidence that specific reduction of the $\alpha 2 \mathrm{~A}$-adrenoceptors in the brainstem exerts anxiolytic-like effects in sham-operated and castrated male rats.
Together, the results of the present study could be also interpreted as that administration of antisense against $\alpha 2 \mathrm{~A}$ adrenoceptors into the region of the locus ceruleus caused anxiolytic-like effect, resulting in an increase in male's attention to the female in the sexual behavior test. This interpretation is supported by the finding that the anxiogenic agent RS-30199 has been shown to fully inhibit the facilitation of male sexual behavior in rats caused by the $\alpha 2$-adrenoceptor antagonist delequamine (Spedding et al., 1998). Moreover, Rowland et al. (1997) found no effect of yohimbine on most aspects of sexual response in sexually functional men. Facilitation of sexual activity under yohimbine in men with erectile problems has been suggested to relate with yohimbic effects on psychological factors that modulate overall sexual response rather than a more selective activation of erectile response.

In conclusion, we have shown that inhibition of $\alpha 2 \mathrm{~A}$ adrenoceptor expression in the region of the locus ceruleus has an anxiolytic-like effect and facilitates male's attention to female in sexual behavior test.

\section{REFERENCES}

Agmo A, Villalpando A (1995) Central nervous stimulants facilitate sexual behavior in male rats with medial prefrontal cortex lesions. Brain Res 696:187-193.

Aoki C, Go CG, Venkatesan C, Kurose H (1994) Perikaryal and synaptic localization of alpha2A-adrenergic receptor-like immunoreactivity. Brain Res 650:181-204.

Bancroft J (1995) Are the effects of androgens on male sexuality noradrenergically mediated? Some considerations of the human Neurosci Biobehav Rev 19:325-330.

Benelli A, Arletti R, Basaglia R, Bertolini A (1993) Male sexual behaviour: further studies on the role of alpha2-adrenoceptors. Pharmacol Res 28:35-45.

Bremner JD, Krystal JH, Southwick SM, Charney DS (1996a) Noradrenergic mechanisms in stress and anxiety. I. Preclinical studies. Synapse 23:28-38.

Bremner JD, Krystal JH, Southwick SM, Charney DS (1996b) Noradrenergic mechanisms in stress and anxiety. II. Clinical studies. Synapse 23:39-51.

Bylund DB, Eikenberg DC, Hieble JP, Langer SZ, Lefkowitz RJ, Minneman KP, Molinoff PB, Ruffolo Jr RR, Trendelenburg AU (1994) International Union of Pharmacology Nomenclature of Adrenoceptors. Pharmacol Rev 46:121-136.

Callado LF, Stamford JA (1999) Alpha2A- but not alpha2B/Cadrenoceptors modulate noradrenaline release in rat locus coeruleus: voltammetric data. Eur J Pharmacol 366:35-39.

Chomczynski P, Sacchi N (1987) Single step method of RNA isolation by acid guanidinium thiocyanate-phenol-chloroform extraction. Anal Biochem 162:156-159.

Clark JT (1991) Suppression of copulatory behavior in male rats following central administration of clonidine. Neuropharmacology 30:373-382.

Clark JT, Smith ER (1984) Enhancement of sexual motivation in male rats by yohimbine. Science 225:847-849.

Clark JT, Smith ER, Davidson JM (1985a) Evidence for the modulation of sexual behavior by alpha-adrenoceptors in male rats. Neuroendocrinology 41:36-43.

Clark JT, Smith ER, Davidson JM (1985b) Testosterone is not required for the enhancement of sexual motivation by yohimbine. Physiol Behav 35:517-521.

Clark JT, Gabriel SM, Simpkins JW, Kalra SP, Kalra PS (1988) Chronic morphine and testosterone treatment. Effects on sexual behavior and dopamine metabolism in male rats. Neuroendocrinology 48:97-104.

Cole JC, Burroughs GJ, Laverty CR, Sheriff NC, Sparham EA, Rodgers RJ (1995) Anxiolytic-like effects of yohimbine in the murine plusmaze: strain independence and evidence against alpha2-adrenoceptor mediation. Psychopharmacology 118:425-436.

Damassa DA, Smith EB, Tennent B, Davidson JM ( (1977) The relationship between circulating testosterone levels and male sexual behavior in rats. Horm Behav 8:275-287.

Dennis T, L'Heureux R, Carter C, Scatton B (1987) Presynaptic alpha-2 adrenoceptors play a major role in the effects of idazoxan on cortical noradrenaline release (as measured by in vivo dialysis) in the rat. J Pharmacol Exp Ther 241:642-649.

Ernsberger P, Meeley MP, Mann JJ, Reis DJ (1987) Clonidine binds to imidazoline binding sites as well as $\alpha_{2}$-adrenoceptors in the ventrolateral medulla. Eur J Pharmacol 134:1-13. 
Fontana DJ, McMiller Jr LV, Commissaris RL (1999) Depletion of brain norepinephrine: differential influence on anxiolytic treatment effects. Psychopharmacology 143:197-208.

Gobert A, Rivet JM, Cistarelli L, Melon C, Millan MJ (1997) Alpha2adrenergic receptor blockade markedly potentiates duloxetine- and fluoxetine-induced increases in noradrenaline, dopamine, and serotonin levels in the frontal cortex of freely moving rats. J Neurochem 69:2616-2619.

Handley SL, Mithani S (1984) Effects of alpha-adrenoceptor agonists and antagonists in a maze-exploration model of "fear"-motivated behaviour. Naunyn Schmiedebergs Arch Pharmacol 327:1-5.

Heal DJ, Butler SA, Prow MR, Bucket WR (1993) Quantification of presynaptic alpha-2 adrenoceptors in rat brain after short term DSP-4 lesioning. Eur J Pharmacol 249:37-41.

Hosoda K, Feussner GK, Fitzgerald LR, Fishman PH, Duman RS (1994) Agonist and cyclic AMP-mediated regulation of alpha1adrenergic receptor mRNA and gene transcription in rat C6 glioma cells. J Neurochem 63:1635-1645.

Hosoda K, Fitzgerald LR, Vaidya VA, Feussner GK, Fishman PH, Duman RS (1995) Regulation of beta 2-adrenergic receptor mRNA and gene transcription in rat C6 glioma cells: effects of agonist, forskolin, and protein synthesis inhibition. Mol Pharmacol 48:206-211.

Jacobowitz DM, Richardson JS (1978) Method for the rapid determination of norepinephrine, dopamine and serotonin in the same brain region. Pharmacol Biochem Behav 5:515-519.

Koskinen I, Hendricks S, Yells D, Fitzpatrick D, Graber B (1991) Yohimbine and naloxone: effects on male rat sexual behavior. Physiol Behav 50:589-593.

La Marca S, Dunn RW (1994) The alpha-2 antagonists idazoxan and rauwolscine but not yohimbine or piperoxan are anxiolytic in the Vogel lick-shock conflict paradigm following intravenous administration. Life Sci 54:PL179-PL184.

Lowry OH, Rosenbrough NJ, Farr AL, Randall RJ (1951) Protein measurement with the Folin phenol reagent. J Biol Chem 193:265-275.

Lucion AB, Charchat H, Pereira GA, Rasia-Filho AA (1996) Influence of early postnatal gonadal hormones on anxiety in adult male rats. Physiol Behav 60:1419-1423.

Marrocco RT, Witte EA, Davidson MC (1994) Arousal systems. Curr Opin Neurobiol 4:166-170.

Mateo Y, Meana JJ (1999) Determination of the somatodendritic alpha2-adrenoceptor subtype located in rat locus coeruleus that modulates cortical noradrenaline release in vivo. Eur $\mathrm{J}$ Pharmacol 379:53-57.

Milner TA, Lee A, Aicher SA, Rosin DL (1998) Hippocampal alpha2aadrenergic receptors are located predominantly presynaptically but are also found postsynaptically and in selective astrocytes. J Comp Neurol 395:310-327.

Peters RH, Koch PC, Blythe BL (1988) Differential effects of yohimbine and naloxone on copulatory behaviors of male rats. Behav Neurosci 102:559-564.

Rago L, Saano V, Tupala E, Nieminen SA, Airaksinen MM (1992) ${ }^{3}$ H-Atipamezole binding sites in mouse cerebral cortex: possible involvement of alpha2-adrenoceptors in sexual behavior. Methods Find Exp Clin Pharmacol 14:23-27.

Rampin O (1999) Pharmacology of alpha-adrenoceptors in male sexual function. Eur Urol 36:103-106.

Robinson ESJ, Nutt DJ, Hall L, Jackson HC, Hudson AL (1999) Autoradiographical and behavioural effects of a chronic infusion of antisense to the $\alpha_{2 \mathrm{D}}$-adrenoceptor in the rat. Br J Pharmacol 128:515-522.

Rowland DL, Kallan K, Slob AK (1997) Yohimbine, erectile capacity, and sexual response in men. Arch Sex Behav 26:49-62.

Sala M, Braida D, Leone MP, Calcaterra P, Monti S, Gori E (1990) Central effect of yohimbine on sexual behavior in the rat. Physiol Behav 47:165-173

Shishkina GT, Naumenko EV (1995) Correlations between the hypothalamic density of ${ }^{3} \mathrm{H}$-clonidine-binding sites and plasma testosterone levels in mice. Neuroendocrinology 61:663-668.

Shishkina GT, Borodin PM, Naumenko EV (1993) Sexual maturation and seasonal changes in plasma levels of sex steroids and fecundity of wild Norway rats selected for reduced aggressiveness towards man. Physiol Behav 53:389-393.

Shishkina GT, Sournina N Yu, Dygalo NN (1997) Sexual behavior and alpha-2 adrenoceptors in the neocortex of male rats after castration and testosterone administration (in Russian). Zh Vyssh Nerv Dejat Im IP Pavlov 47:592-596.

Smith ER, Lee RL, Schnur SL, Davidson JM (1987) Alpha2adrenoceptor antagonists and male sexual behavior. I. Mating behavior. Physiol Behav 41:7-14.

Spedding M, Newman-Tancredi A, Millan MJ, Dacquet C, Michel AN, Jacoby E, Vickery B, Tallentire D (1998) Interaction of the anxiogenic agent, RS-30199, with 5-HT1A receptors: modulation of sexual activity in the male rat. Neuropharmacology 37:769-780.

Szemeredi K, Komoly S, Kopin IJ, Bagdy G, Keiser HR, Goldstein DS (1991) Simultaneous measurement of plasma and extracellular fluid concentrations of catechols after yohimbine administration in rats. Brain Res 542:8-14.

Tallentire D, McRae G, Spedding M, Clark R, Vickery B (1996) Modulation of sexual behaviour in the rat by a potent and selective alpha2adrenoceptor antagonist, delequamine (RS-15385-197). Br J Pharmacol 118:63-72.

Venkatesan C, Song XZ, Go CG, Kurose H, Aoki C (1996) Cellular and subcellular distribution of alpha2A-adrenergic receptors in the visual cortex of neonatal and adult rats. J Comp Neurol 365:79-95.

Weiss JM, Stout JC, Aaron MF, Quan N, Owens MJ, Butler PD, Nemeroff CB (1994) Experimental studies of depression and anxiety: role of the locus coeruleus and corticotropin-releasing factor. Brain Res Bull 35:561-572. 